\title{
Retrato de arquitecto: Mario Pani en la memoria colectiva
}

Graciela de Garay

INSTITUTO MORA/CONACYT

\begin{abstract}
El presente trabajo intenta analizar las representaciones que de Mario Pani (1911-1993) han construido y deconstruido sus colegas arquitectos. Se trata de imágenes y experiencias cambiantes que devienen memoria colectiva por un proceso de consenso social.
\end{abstract}

LA DISTINCIÓN: ¿UNA EDUCACIÓN ESPECIAL?

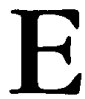

n París, en la Rue Bonaparte y el Quai Malaquais, en la ribera izquierda del Sena, cerca de St. Germain des Prés, se encuentra la famosa Ecole Nationale Supérieure des Beaux-Arts que fundó en Francia Napoleón I, en el año de 1806. Esta institución educativa fue la heredera de la enseñanza de la arquitectura que durante el Antiguo Régimen se impartió en la Academia de Bellas Artes.

En la actualidad, la Escuela Nacional Superior de Bellas Artes constitu- ye un importante centro para la ensenanza de la arquitectura y de las artes plásticas, y cuenta con una intensa actividad académica y cultural abierta a estudiantes, maestros y profesionales del arte, de toda Francia y del mundo entero.

Ahora bien icómo era la vida en esos claustros académicos? ¿Qué se estudiaba? ¿Qué herencia dejó esa escuela? De acuerdo con los programas académicos de 1819, los alumnos de arquitectura de la Escuela de Bellas Artes de París seguían difíciles cursos de matemáticas, de geometría descriptiva, de arquitectura, de historia del 
arte y de las construcciones, así como un curso de historia general, pero no tomaban lecciones de práctica profesional. Los entrenamientos prácticos que existían eran poco concurridos.

En cuanto a las actividades prácticas de los alumnos, se sabe que éstas consistían en realizar ejercicios diarios y aprobar un cierto número de concursos con la idea de obtener un reconocimiento $y$, algún día, el tan deseado Premio de Roma.

A mediados del siglo XIX, las autoridades de la Escuela de Bellas Artes promovieron importantes cambios en el programa de estudios con la idea de acercar el arte y la arquitectura a la industria. En este sentido hay que recordar la competencia que experimentaron los países participantes en las exhibiciones mundiales sobre todo cuando compararon su producción con las contribuciones inglesas, inspiradas en las propuestas de diseño moderno que distinguieron al movimiento Arts and crafts. Congruente con las nuevas tendencias, a partir de 19001901, la Escuela de Bellas Artes añadió a su curriculum las materias de estereotomía, de resistencia de materiales, de geometría-descriptiva, analítica, mecánica y trigonometría. En 19061907 suprimió el curso de reproducción industrial y, a partir de 1913 . 1914, incluyó la aritmética y el álgebra. En 1923-1924 el curso de arquitectura se convirtió en curso de arquitectura decorativa. En 1924-1925 se agregó anatomía, perspectiva, arquitectura, historia general del arte y de la producción industrial. En 1925-1926 se incluyó composición de arquitectura o construcción, que continuó hasta 1932-
1933, justo cuando se agregó la composición de ornamento o composición decorativa. ${ }^{1}$

Ahora bien, los cambios más importantes en la enseñanza y los objetivos de la Escuela de Bellas Artes no se perfilaron sino hasta las décadas de los años veinte y treinta de este siglo, cuando las ideologías sociales radicalizaron el pensamiento arquitectónico. En efecto, en el periodo de entreguerras los contestatarios del arte pugnaron con vehemencia por la expresión de la función, ya fuera para relegar a segundo término o suprimir por completo la preocupación por la belleza. La arquitectura clásica comenzó a mirarse con desconfianza por su individualismo y grandilocuencia irracional; tendencias que contradecían al espíritu democrático de la época. Fue entonces cuando se postuló que la verdadera escala de los edificios no dependía de la estructura individual sino de la ciudad.

La conclusión es que en los espacios de la Escuela de Bellas Artes de París, epítome del gusto neoclásico donde se enseñaba el arte, la teoría estética y la tradición cultural de Occidente, Mario Pani Darqui adquirió la formación académica y la comprensión de la arquitectura como arte. Ingresó a la escuela en el año de 1928, y el 5 de junio de 1934 obtuvo el diploma de arquitecto de la Escuela Nacional Superior de Bellas Artes de París con el tema "Maison au Mexique".

Queda entonces claro que Mario Pani regresó a su país de origen con

${ }^{1}$ Archives, 1978. 
una herencia clásica, formalista, que definía a la arquitectura como arte, sin menospreciar los requerimientos funcionales tales como los datos concretos de la arquitectura, temas que, desde 1890, ya formaban parte del curriculum de la Escuela de Bellas Artes de París. Indudablemente, el joven arquitecto había aprendido a identificar y a utilizar los estilos del pasado, a manejar el lenguaje de las proporciones, de la geometría, de la monumentalidad y, lo más importante, a entender con toda propiedad los principios lógicos de la composición que ahora llaman proyectos. Ciertamente, Pani salía de una escuela de gran prestigio pero, como me explicó Vladimir Kaspé, “...la escuela de Bellas Artes era una escuela que vivía, en los años treinta, sus últimos días de gloria". ${ }^{2}$ Las revolucionarias ideas de Le Corbusier en Francia y las de la Bauhaus en Alemania ya anunciaban nuevas épocas, mismas que tanto Kaspé como Pani absorbieron como espectadores desde la retaguardia. No obstante, Kaspé explicó que en su escuela también hubo dos tendencias: la formalista, que ignoraba la función, y otra, a la que pertenecía su maestro Georges Gromort, que sí se preocupaba por la función. De tal suerte que por distintos caminos, la Escuela de Bellas Artes y el propio Le Corbusier

${ }^{2}$ Entrevista al arquitecto Vladinir Kaspé realizada por Graciela de Garay para el Proyecto de Historia Oral de la Ciudad de México: Testimonios de sus Arquitectos (1940$1990)$ en la ciudad de México, 1 de marzo de 1995, Instituto Mora, PHO 11/16 (1). alcanzaron las mismas conclusiones. ${ }^{3}$ De cualquier manera, no se debe olvidar que para esas fechas ya habían llegado a París los artistas plásticos, los arquitectos y los escritores de vanguardia que, por diferencias ideológicas y deseos de modernidad, habían renunciado a sus pasados nacionales para contribuir a la renovación intelectual y estética del mundo.

\section{LA DISTINCIÓN: ¿VENTAJA O DESVIENTAJA?}

Mario Pani se despidió de Francia en el momento crítico de la transición que marcó el periodo de entreguerras, y llegó a México en otra época también difícil, me refiero a la transición que representó la reconstrucción posrevolucionaria. ¿Qué enfrentó Pani a su regreso?, ¿qué tendencias prevalecían en la Escuela Nacional de Artes Plásticas? y, por tanto, ¿cuáles serían los encuentros y desencuentros que tendría Pani en la Escuela Nacional de Artes Plásticas a la que solicitaría la revalidación de sus estudios de arquitectura, así como el reconocimiento de su título de arquitecto para ejercer en México la profesión?

Efectivamente, el joven arquitecto llegó a un país que se hallaba en proceso de redefinición. Después de 1910, el Estado distinguió las metas nacionalistas como el rumbo principal de sus programas. El compromiso del gobierno estaría en servir al pueblo, imprimir un sentido social a sus programas, buscar la mejoría de las condiciones de vida de la gente, suprimir privilegios,

${ }^{3}$ Thid., 8 de marzo de 1995, PHO 11/16 (2). 
construir un régimen democrático, modernizar la infraestructura económica, productiva, política, social y cultural para integrar al país al concierto de las naciones.

A propósito de los esfuerzos estatales realizados en pro de la educación, conviene mencionar lo relacionado con la educación superior. Efectivamente, en 1929 y nuevamente en 1933 , se expidieron las leyes orgánicas que declararon la autonomía de la Universidad frente al Estado. Esta decisión pareció entregar a la Universidad el pleno control de la educación superior, reservando para el gobierno los niveles primario y medio. Esta repartición de áreas de influencia fue decisiva, porque además de determinar distintos niveles de dominio sobre la producción de recursos humanos, establecía las normas para regir el mercado de trabajo. El Estado estaba convencido de que formar técnicos era lo más urgente para consolidar su programa de modernización. Por tanto, la Universidad, siempre orientada a las humanidades y sin intereses sociales definidos, debería formar a los profesionistas que en ese momento no parecían ser de gran importancia para el país. La Universidad, por su parte, esperaba con su autonomía liberarse de las consecuencias de vaivenes políticos y mantener cierta independencia intelectual y capacidad crítica, pues es claro que en los años treinta el Estado deseaba imponer la educación socialista como base de su programa nacional. Como esto no fue aceptado por la Universidad, el Estado le cortó el subsidio tachándola de reaccionaria. La Universidad Autónoma de México perdía así el carácter nacional con el que se la había fundado en 1910. ${ }^{4}$ Para resistir la penuria y salir adelante en cuanto a sus compromisos educativos, la Universidad modificó sus planes de estudio. En el caso de la enseñanza de la arquitectura, que se impartía en la Escuela de Bellas Artes dentro de su sección de Arquitectura, los profesores que encabezaban la vanguardia, como José Villagrán García en sus clases de teoría de la arquitectura, intentaron imprimir un sentido más social a esta profesión. Pero para comprender mejor la necesidad y sentido de estos cambios conviene recordar brevemente la historia de la Escuela de Arquitectura.

La Escuela de Bellas Artes de México, cuyo antecedente más remoto se halla en la Academia de San Carlos, fundada en Nueva España en 1783 por el rey de España Carlos III, siguió una historia similar a la Escuela de Bellas Artes de Francia. En su primera época, los cursos en ambas escuelas hicieron énfasis en los aspectos estéticos y en los principios neoclásicos; las matemáticas eran ineludibles, desde luego. En la segunda época las dos academias se impregnaron de las nuevas teorías de la arquitectura que hablan de la verdad y de la sinceridad y, por tal motivo, dieron gran énfasis a la composición y al dibujo geométrico al servicio de la arquitectura. Tan es así, que todavía en 1992 Teodoro González de León, ex alumno de la Escuela de Arquitectura de la UNAM, lamentaba que ya no se enseñara geometría y estereotomía en la Facultad de Arquitectura, bases fundamentales para apren-

${ }^{4}$ Arce, "Inicio", 1982, pp. 261- 263. 
der a descomponer el espacio, hacer cortes de sólidos y buenos proyectos. "No, ahora ya no saben nada", 5 comentó con enojo el arquitecto.

Efectivamente, si uno compara los planes de estudio de ambas escuelas, encuentra que no existe diferencia curricular seria, y que México, a pesar de sus propuestas nacionalistas, continuó mirando a Francia por lo que toca a la educación artística. ${ }^{6}$ Pero ahora vuelvo al asunto que me ocupa: Mario Pani y la revalidación de sus estudios y diploma de arquitecto.

Antes de comenzar vale la pena advertir que fue precisamente el año de 1933 cuando por primera vez la Universidad Nacional Autónoma de México efectuó un trámite formal de revalidación. Esto se hizo ante la necesidad urgente que tenían la Universidad y el propio país de contar con profesionales capacitados para ocupar los nuevos cargos públicos y privados que demandaba el crecimiento económico de la nación. Ante estas circunstancias, se estableció un proceso por el que se encomendaba a unà comisión analizar y valorar los documentos en cuestión para recomendar al Consejo Universitario la revalidación y el reconocimiento del título en caso de que dichas solicitudes procedieran.

' Entrevista al arquitecto Teodoro González de León por Graciela de Garay para el Proyecto de Historia Oral de la Ciudad de México: Testimonios de sus Arquitectos (1940-1990), ciudad de México, 29 de agosto de 1991, Instituto Mora, PHO 11/10(2).

${ }^{6}$ Revisar en el Archivo Histórico del Centro de Estudios sobre la Universidad (en adelante AHCEU), fondo Escuela Nacional de Artes Plásticas, cajas $17,20,21$.

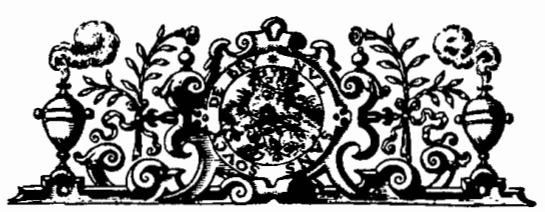

El 23 de julio de 1934, Mario Pani dirigió una carta al rector de la Universidad Nacional de México, Manuel Gómez Morín, para exponerle:

que ha hecho en la Escuela Nacional y Superior de Bellas Artes de París, Francia, los estudios y prácticas que la ley respectiva exige para la carrera de arquitecto y obtenido el diploma correspondiente; $y$, en tal virtud, a usted, $\mathrm{C}$. rector, suplica se sirva librar sus órdenes para que le sea revalidado dicho diploma y pueda ejercer en México la mencionada profesión. ${ }^{7}$

El 31 de agosto de 1934, Antonio Armendáriz, oficial mayor de la Universidad Nacional de México, solicitó al director de la Facultad de Filosofia y Bellas Artes, sección de Arquitectura, que estudiara la competencia de la revalidación que pedía Mario Pani, "en la inteligencia, decía Armendáriz, de que el citado plantel es de primer orden $y$ sus estudios están fuera de cualquiera discusión".

${ }^{7}$ AHCEU, fondo Asuntos generales, exp. Mario Pani, núm. 2053.

${ }^{8}$ Ibid. 
Iniciada la evaluación de los documentos para su revalidación, el día 13 de octubre de 1934 Manuel Gómez Morín, rector de la Universidad; envió a Antonio Armendáriz, oficial mayor, un memorándum en el que le solicitaba preparar un informe sobre las razones de la Comisión para decidir su dictamen, así como de las consideraciones expuestas por el arquitecto José Villagrán García. A su comunicado, el rector anexaba un recado del arquitecto Villagrán que decía lo siguiente:

Señor, abogado Gómez Morín:

No habiendo tenido la suerte de encontrarle esta mañana, le suplico tomar nota de este asunto: .

1) La revalidación de estudios del señor Mario Pani ha sido acordada por la comisión con criterio diverso al sustentado para otros casos: el del señor Julio Vigil, por ejemplo.

2) Si se revalidan grados o títulos ¿por qué no se considera en todos los casos los estudios para juzgar si cubren nuestros planes?

3) El caso de Pani no cubre el plan como el caso Vigil, y en un caso sc revalida el título y en el otro se exigen estudios, no obstante ser pensionado por el gobierno mexicano.

4) El desconocimiento de nuestros problemas y medio físico mexicanos imposibilita el ejercicio profesional. ¿La Universidad desconoce esto?, ¿'anzará irresponsables a la vida prá ztica por estas divergencias explicables sólo en planos no leales?

Le suplico evitar a la Universidad las consecuencias públicas del caso, que serán sensibles y jugosas babiendo de por medio un nombre conocido en política.
Gracias por su atención, lo saluda muy afectuosamente

\section{J. Villagrán. ${ }^{9}$}

Efectivamente, Villagrán estaba en lo correcto cuando señalaba que Pani no había tenido cursos que lo prepararan para el mejor conocimiento de los problemas y el medio físico mexicano. Sin embargo, su argumento no tenía mucha base si, por un lado, se revisan los planes de estudio de la Escuela Nacional de Arquitectura y, por otro, se advierte que en 1931-1932 el Estado, por su cuenta, ya había comenzado a resolver el problema de la formación técnica al crear la Escucla Superior de la Construcción. En esta institución se abrieron las carreras de ingeniero constructor, proyectista técnico y constructor técnico. Para lograr la especialidad en ingeniería, los alumnos deberían hacer una carrera de cuatro años, y para ingresar se les exigía como prerrequisito la preparatoria técnica, igualmente de cuatro años. ${ }^{10} \mathrm{En}$ el periodo cardenista esta escucla se transformaría en la Escuela Superior de Ingeniería y Arquitectura (ESIA) del Instituto Politécnico Nacional. Con la fundación de la Escuela Superior de la Construcción se marcaron dos corrientes distintas en la cultura arquitectónica de México: la de los funcionalistas integrales que hacían énfasis en la función sin descuidar la belleza, y la de los funcionalistas radicales, que hablaban de la arquitectura como una técnica dedicada a resolver la función. Dentro de esta última tendencia

\footnotetext{
9 Ibid.

${ }^{10}$ Arce, "Inicio", 1982, p. 259.
} 
no se inscribía la belleza, precisamente por considerarla una carga burguesa. Además, la ideología socialista constituía un fuerte componente de su teoría. Así, mientras en la Universidad, a principios de los años treinta, se empezaban a impugnar los postulados beaux-arts, en la. escuela de la SEP la posición era tajante: se luchaba por la eliminación de los conocimientos humanísticos propios de la Universidad, incluyendo a la estética, para postular a la técnica como el único instrumento adecuado para enfrentar las necesidades edilicias de la población; al mismo tiempo, los programas anunciaban una orientación bien clara y definida hacia los sectores sociales mayoritarios. Se trataba sin duda de una posición antielitista. ${ }^{11}$ Años después, Juan O' Gorman -uno de los más importantes impulsores de la escuela de la línea técnica de la arquitectura- diría que el objetivo de esta institución era producir "ingenieros de edificios", en lugar de arquitectos tradicionales. ${ }^{12}$

El 7 de septiembre de 1934, Enrique O. Aragón, director de la Facultad de Filosofía y Bellas Artes de la Universidad Nacional de México, envió al señor abogado Antonio Armendáriz, oficial mayor de la Universidad $\mathrm{Na}$ cional, un oficio relativo a la revalidación del título de Mario Pani en el que le comunicaba lo siguiente:

Tengo la honra de contestar a usted su oficio No. 150-4370, exp. 150/213.1/, relativo al señor Mario Pani, quien desea revalidar su título de arquitecto otor-

${ }^{11}$ López, Enrique, 1982, p. 22.

${ }^{12}$ Luna, Juan, 1973. gado por la Escuela de Bellas Artes de París (Francia), y sancionado por el director de la misma institución, a nombre del Ministro de Educación Nacional.

Con este motivo entrevisté al señor Arq. José Villagrán García, jefe de la Sección de Estudios Arquitectónicos de esta facultad, quien me indicó que $l a$ revalidación de estudios podría aceptarse; pero sin el otorgamiento de grado, porque el señor Pani se ba encontrado en un medio diverso del existente aqui, en que es necesario el conocimiento de la legislación propia del país, de la arquitectura nacional o sea en relación con las necesidades de nuestro ambiente $y$, por ultimo, las especificaciones fundamentales teniendo en cuenta la naturaleza del subsuelo y sus condiciones geológicas; de modo que se necesita este complemento para la persona proveniente del extranjero.

Con todo respeto me permito disentir de la opinión del señor Arq. Villagrán Garcia. Si la Universidad de México no revalida los títulos de arquitecto de una de las mejores instituciones del mundo, como es la francesa, no sé qué pueda revalidar, esto es por un lado, y por el otro, entiendo que el señor Pani seguramente no desconoce estos datos propios de la localidad y a los que se refiere el señor Arq. Villagrán García.

Además, quedarían los estudiantes mexicanos que van a Europa y se reciben alli en corporaciones de primer orden, en malas circunstancias, poniéndoles dificultades y aun negándoles el ejercicio profesional en su propia patria. Quedarian en condiciones inferiores a las de extranjeros que al llegar al país les revalidan sus créditos y se les permite ejercer con los requisitos que señalan nuestras leyes.

Por tales motivos me permito significar a la superioridad, para que ella 
tenga a bien resolver, que a mi juicio es de revalidarse el título de arquitecto expedido al señor Mario Pani por la nación francesa.

Protesto a usted las seguridades de mi atenta consicleración

Por mi raza hablará el espíritu.

México, D.F., a 7 de septiembre de 1934.

Doctor Enrique O. Aragón. ${ }^{13}$

Cabe mencionar que en los planes de estudio de la Escuela Nacional de Bellas Artes, correspondientes a los años de 1928, 1930 y 1931, se enseñaban materias como geometría descriptiva y trazado de sombras, dibujo preparatorio del natural, mecánica general y cálculo gráfico, ornato modelado, teoría de la arquitectura, estereotomía, historia del arte, composición de elementos de los edificios, composición decorativa, conferencia de urbanismo. ${ }^{14}$ Con apoyo en este listado se pueden apuntar coincidencias con la Escuela de Bellas Artes de París. Además, es posible probar que los estudiantes de arquitectura de la Universidad Nacional tampoco disponían de las herramientas necesarias para enfrentarse a su medio. Si bien es cierto que en los planes de estudio de 1930 y 1931 los alumnos del tercer año llevaban una clase de construcción, primer curso (estructuras de hierro y concreto armado, estudio del subsuelo mexicano, cimentación) y los del quinto año cursaban una materia de urba-

\footnotetext{
${ }^{13}$ AHCEU, fondo Asuntos generales, exp. Mario Pani, núm. 2053.

${ }^{14}$ Universidad, Plan, 1928; Universidad, Plan, 1930. Véase también Katzman, Arqui. tectura, 1963-1964, pp. 99-128.
}

nismo y otra de presupuestos, avalúos y legislación de construcciones, la proporción del número de las materias técnicas con respecto a los cursos artísticos era más bien inferior. Es más, como explica López Rangel, en estos programas se trasluce la arquitectura como una problemática artística plástica, a la manera como entendía el arte el pensamiento beaux-arts. Se observa además una escasa dosificación técnica constructiva y apenas una brizna de urbanismo. ${ }^{15}$

La situación es que aun cuando Villagrán representara la modernidad por sus obras arquitectónicas y por sus aportaciones teóricas, el maestro adquirió mucho de su formación básica de la Escuela de Bellas Artes de París. Baste ver cómo sus lecturas de Guadet y Viollet-le-Duc influyeron en su pensamiento teórico-crítico. Por otra parte, sus contribuciones al movimiento moderno, como la Granja Sanitaria (1926) o el Sanatorio para Tuberculosos de Huipulco, son un tanto cuanto tardíos en relación con la Semana del Arte Moderno organizada en Brasil en 1922. Como diría Teodoro González de León, en otras actividades los desfases cronológicos de uno o dos años pueden no significar nada, pero en el arte, y especialmente en la arquitectura, representan un mundo de cambios. ${ }^{16}$

\footnotetext{
"López, Enrique, 1989, pp. 22-24.

${ }^{16}$ Entrevista al arquitecto Teodoro González de León realizad a por Graciela de Garay para el Proyecto de Historia Oral de la Ciudad de México: Testimonios de sus Arquitectos (19401990), ciudad de México, 19 de marzo de 1992, Instituto Mora, PHO 11/107(7).
} 
La verdad de las cosas es que las exigencias de Villagrán no eran fundamentales, sobre todo porque Mario Pani tenía en su haber una formación práctica y estética muy sólida. El hecho es que arquitectos de todo el mundo, y principalmente de Estados Unidos, se matricularon, desde el siglo XIX, en la Escuela de Bellas Artes de París para reforzar sus conocimientos técnicos y formales.

Después de largas discusiones, el 2 de octubre de 1933 el rector de la Universidad Nacional de México, Manuel Gómez Morín, estableció por acuerdo lo siguiente.

Con fundamento en el artículo $15 \mathrm{del}$ Reglamento de Revalidación de Estudios, revalídense al señor Mario Pani Darqui, los estudios correspondientes a su diploma de arquitecto expedido por la Escuela Nacional de Bellas Artes de Paris, Francia, el 5 de junio de 1934, para que dicho diploma surta los mismos efectos que los de arquitecto de esta Universidad.

El rector

Manuel Gómez Morín. ${ }^{17}$

Después de analizar este proceso de revalidación, vale la pena preguntarse en qué medida las posiciones adoptadas a lo largo de este procedimiento reflejaban un asunto académico o un problema para la sociología de las profesiones. Sobre todo si se considera que las profesiones son una manera de mantener el orden dentro de la sociedad, en tanto estrategia de división del trabajo.

${ }^{17}$ AHCEU, Asuntos generales, exp. Mario Pani, núm. 2053.
LA CONSTRUCCIÓN DE IA MEMORIA

COLECTIVA DOMINANTE Y LA

DECONSTRUCCIÓN DE LA DIFERENCIA

Hay biografías en las que parecen conjugarse simultáneamente los privilegios del azar, favorable y exclusivista, con los obstáculos y pruebas de la necesidad, siempre limitante y adversa a los deseos de una vida. La historia de Mario Pani es un modelo de esta paradoja. Si se pudiera comparar o calibrar el número de metros construidos con las montañas de conflictos y polémicas cosechadas a lo largo de esa vida, resultaría incomprensible el éxito logrado a contracorriente, y muy comprensible la ambigüedad del reconocimiento finalmente obtenido.

Desde luego, el curriculum del arquitecto es extenso por el volumen de obras y por la importancia de éstas en su tiempo; sin embargo, aunque los premios se hicieron llegar, éstos se le concedieron en circunstancias más bien extrañas. Vale la pena recordar que cuando le otorgaron el Premio de la Academia Nacional de Arquitectura en 1985, precisamente después del terremoto que por cierto afectó gran parte sus edificios, y el Premio Nacional de Ciencias y Artes de Bellas Artes en 1986, Pani se encontraba prácticamente retirado; formaba parte de las elites formales que operaban sin poder político pero con influencia gremial que, aunque limitada, era lo suficiententemente evidente para incidir en los rumbos de la Academia de Arquitectura. Dadas las circunstancias descritas, cualquier historiador se podría preguntar por qué las distinciones habían llegado tan tarde y en tan mal 
momento. ¿Por qué de pronto el Estado valoraba a Pani, su arquitecto de tantos años, cuando la crítica siempre se había negado a hacerlo?

La verdad es que el inventario de proyectos y construcciones de Mario Pani es enorme, y para dar una idea resumiré en unas cuantas líneas su historia. Fue maestro de la Escuela Nacional de Arquitectura y de la Universidad Anáhuac; asesor y consejero de diversos programas públicos de vivienda y urbanos del país; fundador de la revista Arquitectura-México que duró más de cuarenta años (1938. 1979); recibió el Gran Premio de la Academia Nacional de Arquitectura en 1985 y el Premio Nacional de Ciencias y Artes de Bellas Artes en 1986; además, fue miembro de la Sociedad de Arquitectos de México en 1940 y miembro fundador del Colegio Nacional de Arquitectos de México en 1946; fundador y miembro de la Academia Nacional de Arquitectura, así como académico de número de la Academia de Artes.

Su vida profesional abarcó 40 años. En la primera etapa de su carrera (19351945) se distinguió como arquitecto del sector privado. En este periodo proyectó residencias, apartamentos y hoteles; trabajó como profesor de la Escuela Nacional de Arquitectura de la UNAM y se inició como arquitecto público con el diseño de hospitales, escuelas y oficinas; en la segunda etapa (1945-1965) ejecutó las primeras unidades habitacionales en altura que se erigieron en el país, y promovió la primera ley de condominios que hubo en México para atender el problema de la morada pública y privada, pero, fundamentalmente elaboró proyectos urbanos que el mismo arquitecto definió como "ciudades dentro de la ciudad" (Ciudad Universitaria, Ciudad Tlatelolco), o como "ciudades fuera de la ciudad" (Ciudad Satélite); también proyectó planes reguladores para diversos centros urbanos del país y, finalmente, en la tercera etapa (1965-1975) realizó como arquitecto su última gran obra, el hotel Condesa del Mar en Acapulco (1970), y como urbanista el Plan Maestro para la Reconstrucción de Managua, Nicaragua, en 1974. En las décadas que precedieron a su muerte siempre hizo sentir su influencia intelectual a través de sus participaciones en la Academia Nacional de Arquitectura, en la Academia de Artes, en el Colegio de Arquitectos y, en particular, con la elaboración de propuestas para el rescate del Centro Histórico de la ciudad de México y la reordenación urbana de la capital mexicana.

Después de entrevistar a 16 arquitectos mexicanos ${ }^{18}$ de dos generaciones consecutivas o, mejor dicho, per-

${ }^{16}$ Entrevistados del Proyecto de Historia Oral de la Ciudad de México: Testimonios de sus Arquitectos (1940-1990), patrocinado por el Instituto Mora, con el apoyo de Conacyt, comprende una lista de 17 incluyendo a Mario Pani: Enrique Yáñez (1908-1991), Héctor Mestre (1909), Félix Candela (1910), Vladimir Kaspé (1910-1996), Mario Pani (1911-1993), Manuel de la Colina (1913), Augusto H. Álvarez (1914-1995), Ernesto Gómez Gallardo (1917), Reinaldo Pérez Rayón (1918), Pedro Ramírez Vázquez (1919), Ricardo de Robina (1919), Agustín Hernández (1924), Abraham Zabludovsky (1924), Teodoro González de León (1926), Jaine Ortiz Monasterio (1928), Luis Ortiz Macedo (1933), Juan José Díaz Infante (1936). 


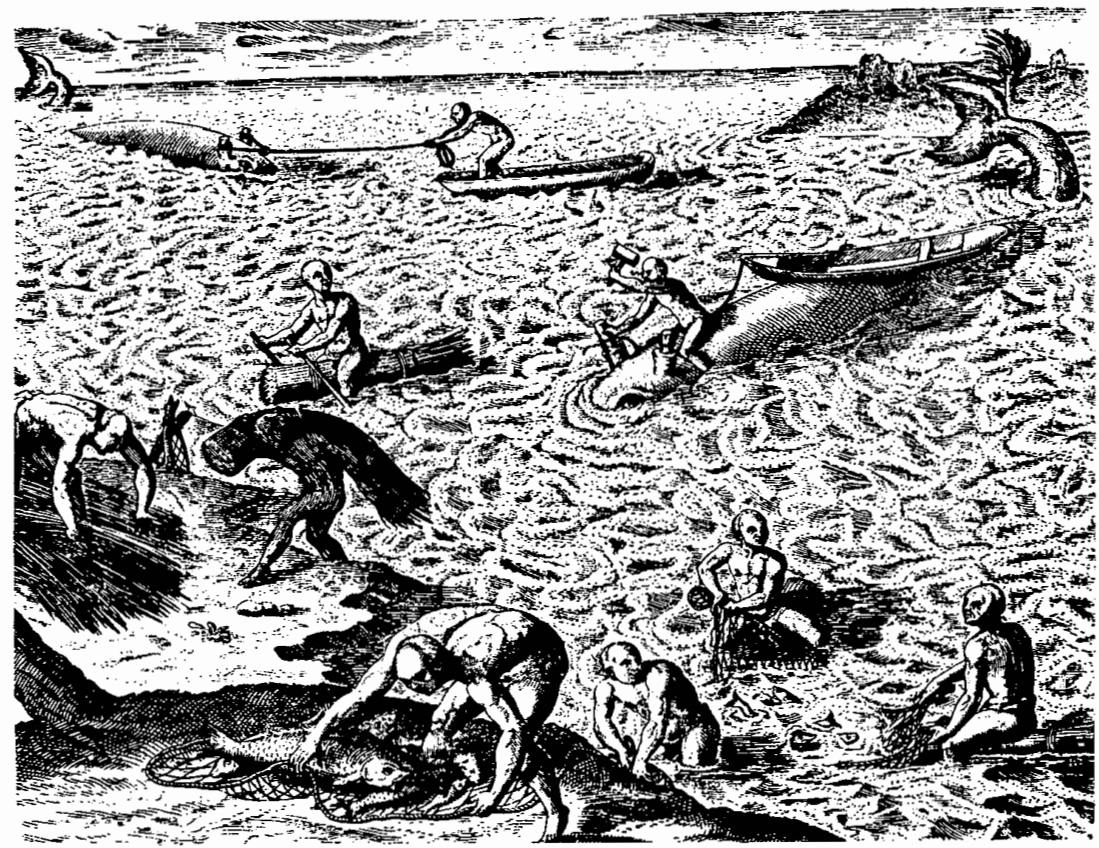

tenecientes a dos cohortes generacionales distintas, unidas por la historia y la experiencia profesional más que por la edad biológica, descubrí en sus relatos la repetición constante de un leitmotiv o mito, alrededor del cual estos grupos construían diversas y hasta antagónicas representaciones del arquitecto Mario Pani.

A partir de las representaciones sociales registradas en las entrevistas, es decir, de esas imágenes complejas que reúnen un conjunto de significados, sistemas de referencia o categorías derivados del sentido común y que sirven para clasificar a los individuos con quienes nos relacionamos, ${ }^{19}$ percibí fundamentalmente dos historias, o dos hombres distintos, que retrataban al mismo arquitecto Pani.

Las representaciones contenidas en las narraciones habían llegado a formar en su conjunto una memoria colectiva. Esto quiere decir que las memorias individuales se combinaron y, luego de ser sancionadas por otras historias narradas desde posiciones y perspectivas distintas dentro de un mismo proceso colectivo, inte475 .

19 Jodelet, "Representación", 1984, pp. 472 - 
graron una narración aparentemente uniforme y dominante, cuya exploración cuidadosa expondría algún día las contradicciones internas de ese recuerdo oficial.

En efecto, con estas impresiones tan ambiguas se dibujaban las dos imágenes de Pani, ya fuera la del filántropo de la salud de la ciudad, o la del egocéntrico defensor de las fuerzas del mercado como lo es cualquier planeador; la del teórico del buen desarrollo de su oficio, o la del intuitivo, heredero irracional de teorías apenas aprendidas e incomprendidas; la del humanista, consciente de los valores o derechos del hombre, o la del tecnócrata, dispuesto a glorificar las reglas del mercado sin considerar el valor humano; la del arquitecto, como individuo dedicado a la belleza, preocupado por unir materiales, funciones y finalidades, o la del empresario-especulador, apenas consciente de la pérdida de su quehacer, interesado exclusivamente en la refuncionalización del espacio para su mejor rentabilidad $y$, finalmente, la del nacionalista preocupado por la modernización de su patria para el beneficio de sus contemporáneos, o la del híbrido extranjerizante, ajeno a su pasado y a su realidad. Ante versiones tan controvertidas ¿qué podría hacer yo para construir, o mejor dicho, comprender identidad tan compleja? Lógicamente no se trataba de escoger una verdad e imponerla por arriba de todas; salida fácil pero obviamente parcial y poco respetuosa de la verdad de mis interlocutores. Por el contrario, la alternativa más aconsejable, si realmente se perseguía reconstruir o llegar a una verdad, sería reconocer la pluralidad de todas las versiones reunidas. El objetivo sería, a partir de la crítica y de la reflexión, alcanzar una interpretación más inclusiva que, al comprender los porqués de los distintos puntos de vista involucrados, cristalizara en una verdad, si no definitiva, al menos más compleja y abierta.

Convencida de la importancia de los testimonios para la construcción de la verdad histórica a pesar de sus encontradas diferencias iqué podía colegirse de tal contradicción? Esencialmente dos conclusiones: primero, que una memoria colectiva compartida por un grupo cuenta con distintos significados o interpretaciones, dependiendo de dónde habla y a quién habla el narrador. En suma, el relato es un asunto de la memoria, porque no hay una adecuación o correspondencia de lo narrado con lo vivido. "La memoria plasmada en el relato no se sujeta a lo vivido, sino que lo recrea en función de los contextos prácticos en los que se sitúa el que cuenta."20 Por eso, contar la historia de Pani es contar la historia de su memoria, así como la historia de las memorias que lo narran. La segunda conclusión es que en esas interpretaciones multidimensionales se inscriben datos o pistas ocultos detrás de la situación del narrador. De ahí que me decidiera por las verdades plurales como la estrategia más recomendable para interpretar la compleja realidad humana que analizaba. Por tanto, más interesante resultaba entonces conocer la construcción, la dinámica y el sentido

${ }^{20}$ Mendiola, "Michel", 1993, p. 10. 
de esas representaciones, auténticos mitos o leyendas de Pani que, dicho sea de paso, han prevalecido desde el ingreso de éste a la vida profesional, hace más de 50 años. Emprender este camino era adentrarse en el estudio de una cultura para la mejor comprensión de sus prácticas sociales. Pero, ¿cómo investigar la conformación, la selección, la transmisión, el funcionamiento y los sentidos de la memoria colectiva?, en fin iqué reglas o métodos tendría que seguir para descifrar la intrincada trayectoria de la vida estudiada?

Pues bien, habría que comenzar por investigar la construcción de la memoria colectiva dentro del gremio arquitectónico, a partir de los relatos elaborados por los distintos testigos y actores que participaron en el proceso de revalidación de los estudios y el reconocimiento del título de arquitecto de Mario Pani. Esta vía permitiría destacar, por una parte, la variedad de puntos de vista y, por otra, los intereses representados por las diversas clases de informantes. Pero antes que nada, habría que reparar en lo que constituye propiamente el proceso de construcción de la memoria colectiva.

De acuerdo con los expertos, la práctica de contar historias dio origen a la construcción y a la narración de la memoria, antecedentes naturales de la crónica y de la historia. El contador de historias, escribió Walter Benjamin, toma lo que conoce de la experiencia -ya sea la suya propia o la de otros-, y luego la transforma en la experiencia de aquellos que escuchan la historia. ${ }^{21}$

${ }^{21}$ Benjamín, "Storyteller", 1955, p. 87.
Como dice David Thelen, el contador de historias y su audiencia son socios o cómplices en la construcción de la memoria que se cuenta. En el curso de la conversación cotidiana, los narradores controlan muy claramente la atención de sus escuchas al decidir y seleccionar qué elementos recordar, cómo organizar e interpretar esos elementos y, finalmente, cómo hacer la memoria pública. ${ }^{22}$ Así, el diario acontecer transcurre acumulando eventos insignificantes que de pronto trascienden las fronteras de lo banal y se singularizan por el simple acto de pensarlos para uno mismo o por contarlos a otros. Al narrar este pensamiento, las imágenes se convierten en lenguaje y con ello se intregran a la cultura. La memoria deviene colectiva.

Pero también es cierto que no es suficiente comunicar un recuerdo, se necesita transmitirlo o heredarlo a las generaciones futuras para que se transforme en memoria colectiva. Su transmisión en el tiempo depende del consenso social para su legitimización. Las memorias transgresoras de ese consenso colectivo nunca se integran a los scripts o guiones oficiales de una comunidad; por el contrario, al reprimirse se hallan ocultos en esas narrativas que, valiéndose de la retórica, "dicen lo que no se dice". Pues si bien es cierto que la grámatica dicta las reglas de la sintaxis, la retórica las contradice.

El hecho es que los relatos contradictorios del discurso oficial nunca encuentran espacio para expresarse porque la convivencia con éstos les resulta intolerable a sus contemporá-

\footnotetext{
22 Thelen, Memory, 1990, p. virr.
} 
neos. Por tal motivo, hay que dilucidar en ese entramado complejo de historias aquellas que la memoria colectiva tiende a olvidar, corregir y ajustar en ese proceso de selección que a diario realizan los que cuentan y escriben la historia.

Ahora bien, aceptado que la memoria colectiva se construye en el diálogo con el otro, habría que recordar, una vez más, cómo se recibió el caso de Pani en el interior del Consejo Universitario y cómo las discusiones al respecto de alguna manera se socializaron entre los diferentes grupos que, además de defender pareceres distintos, los compartieron con sus colegas y los heredaron a las generaciones siguientes. El resultado aparentemente benefició al grupo partidario de Pani, que votó por la revalidación de los estudios y el reconocimiento del título pero, paradójicamente, le rindió mayores ganancias al sector derrotado, pues fue éste, el grupo de Villagrán, el que a la postre construyó la memoria colectiva dominante, de la que todavía se escuchan los argumentos clave, otra vez esgrimidos contra Pani: "su total ignorancia e incomprensión de la realidad del país".

En efecto, volviendo a la historia, vale la pena recordar que José Villagrán García, el director de la Escuela de Arquitectura, considerado en ese momento como el teórico de la modernidad y, por tanto, se podría decir el representante más autorizado del gremio, se declaró contrario a la solicitud. Admitió la revalidación pero rechazó el reconocimiento del título. ¿Qué significó este criterio? Como ya se explicó, desde el punto de vista académico las objeciones presentadas por el director de Arquitectura no eran definitivas. Cabe subrayar que, hacia 1890, importantes reformas académicas ya se habían implantado en la Escuela de Bellas Artes de París, cambios que la acercaron a las modernas preocupaciones teóricas, prácticas, técnicas y estéticas que discutían los arquitectos de la época. De tal suerte que los estadunidenses, muchos de ellos ex alumnos de l'Ecole des Beaux-Arts, continuaron defendiendo y tomando como referencia los planes de estudios y criterios de la escuela francesa, principalmente aquellos que se referían a la composición. ¿Dónde estaba el problema entonces?, en todo caso ¿qué podría explicar la desconfianza o la sospecha de Villagrán?

Después de leer el recado que Villagrán envió al rector de la Universidad, Manuel Gómez Morín, sc pueden derivar dos reflexiones. Primero, las quejas sobre la falta de formación de Pani estaban mal fundamentadas $y$, segundo, predominaban los juicios de valor a nivel personal en las impresiones que el director de la liscuela de Arquitectura se había forjado de Pani a través de la familia de éste como representante de la elite política prepotente del periodo posrevolucionario, acostumbrada a proceder arbitraria e irresponsablemente. ¿Qué había detrás de esta representación? Las prácticas éticas o los códigos de honor de un grupo que defendía la construcción de otro orden legal en el país, libre de la corrupción política y quizá más profesional, sobre todo si se atiende el reclamo de Villagrán en cuanto a que no se había sido justo 
con el caso de la revalidación de estudios del alumno Vigil. Aunque en apariencia sus razones tenían un fondo de verdad, me parece que su razonamiento no fue del todo persuasivo, tal vez por su vehemencia y falta de argumentación. Otro aspecto a considerar dentro de la discusión es que, para los años treinta, el nacionalismo mexicano ya había tomado otros caminos, se había abandonado la tendencia extrovertida que idealizaba lo propio, ahora se miraba hacia adentro para conocer nuestros defectos, ese "complejo de inferioridad del mexicano", y así ver cómo nos incorporábamos mejor al ámbito internacional. ${ }^{23}$ El nacionalismo cerrado no tenía sentido, ya que ni el propio Villagrán lo practicaba; de hecho era él un gran admirador de la arquitectura francesa.

La verdad es que acceder al reconocimiento del título de Pani significaba, a ojos de Villagrán, permitir que la Universidad ejerciera descuidadamente ese poder que le había conferido el Estado para decidir quiénes tenían derecho a ingresar al mercado de trabajo profesional. El gobierno se había reservado el derecho de controlar la educación elemental, media y técnica, mientras que a la Universidad le había entregado la educación superior. Pero también es cierto que en el Consejo Universitario los intereses estaban divididos, y las decisiones sobre esta selección de profesionales nunca sería homogénea ni fácil de demarcar.

Por otra parte, habría que considerar los perfiles, los vínculos sociales y los compromisos políticos de los suje-

${ }^{23}$ Villoro, "Cultura", 1992, pp. 249-250. tos que apoyaron a Mario Pani en los trámites de revalidación de estudios y reconocimiento de título. Primero, habría que mencionar que Alberto J. Pani, tío de Mario Pani, luchó contra la dictadura de Porfirio Díaz y que, en la época posrevolucionaria, ocupó importantes cargos políticos, como secretario de Instrucción Pública, de Industria y Comercio, de Relaciones Exteriores y actuó como secretario de Hacienda en los gobiernos de los presidentes Álvaro Obregón, Plutarco Elías Calles, Pascual Ortiz Rubio y Abelardo Rodríguez. 'También es importante tomar en cuenta su participación como empresario privado en la vida económica y en los negocios del país. A partir de bosquejo tan sucinto, se pueden inferir las redes sociales, el poder y las lealtades que respaldaban a Alberto J. Pani dentro de su contexto.

También resulta importante explicar que Arturo Pani, padre de Mario Pani, fue miembro del Servicio Exterior Mexicano desde 1918 hasta 1934, cuando fue cesado de sus funciones por problemas con el grupo callista. No obstante el rompimiento con este círculo, los Pani mantuvieron sus relaciones con la elite política.

En cuanto a Manuel Gómez Morín, se puede indicar rápidamente que estudió leyes en la Universidad Nacional; ahí formó parte del grupo de jóvenes conocidos como "Los siete sabios" y luego fue secretario de la Universidad. Fue consejero en materias jurídicas y económicas de los presidentes Álvaro Obregón y Plutarco Elías Calles. Ocupó el cargo de rector de la Universidad del 23 de octubre de 1933 al $26 \mathrm{del}$ mismo mes del año siguien- 
te. En 1934 la Universidad Nacional Autónoma de México le otorgó el primer doctorado honoris causa. Además, durante su periodo como rector se opuso terminantemente al artículo III y, por supuesto, a la imposición de la enseñanza socialista en la Universidad de México. En 1939 Gómez Morín fundó el Partido Acción Nacional, de oposición al régimen revolucionario; presidió ese organismo político de 1939 a 1949. Estos datos sugieren, por un lado, las relaciones de Gómez Morín con Alberto J. Pani, quien, ya se explicó, ocupó cargos políticos importantes $y$, por otro, hacen pensar en las posibles lealtades que unieron a ambos políticos. Tampoco hay que perder de vista que la Universidad, en la época de Gómez Morín, entendía como su tarea primordial la formación de los profesionales capacitados para emprender la modernización del país, mientras que el Estado se interesaba exclusivamente por la educación de los técnicos.

Antonio Armendáriz, el oficial mayor de la Universidad, era un abogado también identificado políticamente con Manuel Gómez Morín, maestro de la preparatoria y buen conocedor de la política.

Enrique $O$. Aragón fue director de la Facultad de Filosofía y Letras y representante del Consejo Universitario en 1934. También se encargó interinamente de la Rectoría de la Universidad. En la Facultad de Filosofía se encontraba el Consejo Universitario, máxima instancia para dictaminar los trámites de revalidación. El doctor Aragón fue neuropsiquiatra, famoso por sus investigaciones en psicología experimental, pero totalmente ajeno a la arquitectura.
El caso es que la revalidación de estudios y el reconocimiento del título de arquitecto de Mario Pani fue una decisión del Consejo Universitario, a pesar del disgusto del gremio de los arquitectos. Indudablemente, el ingreso de Pani a la vida profesional fue avalado por otros intereses, otras lealtades y, desde luego, otros grupos políticos y profesionales, que no eran precisamente los de los arquitectos. EI reclutamiento de Mario Pani forma parte del proceso que podríamos definir como recirculación de las elites políticas. Ahora ya nadie habla de este episodio y quizá hasta lo hayan olvidado. Pero lo que sí me queda claro es que las consecuencias del incidente todavía perduran en las representaciones sociales que se han heredado de Mario Pani. Incluso, el propio Pani me lo hizo saber cuando me comentó lo siguiente:

Bueno, mire, en los primeros años, mi relación con los arquitectos (se refiere a José Villagrán y a su grupo) fue muy, muy pobre, porque precisamente me veían... me veían así... como con cierto fastidio... entonces me dediqué a entrar a todos los concursos... y después ya me adoptaron, me aceptaron y formé parte de ellos... pero siempre hay ciertas reacciones... Mire, le digo esto: si hubiera sido extranjero, realmente extranjero, yo hubiera tenido esperanzas; pero yo no era ni extranjero, ni mexicano; era un bíbrido dudoso, al cual se le envidiaba o se le creía incapaz, o afrancesado, en fin, no mexicano, en fin, toda una seriè de calificativos negativos. ${ }^{24}$

${ }^{24}$ Entrevista al arquitecto Mario Pani realizada por Graciela de Garay, para el Proyecto de 
Tal parece que Mario Pani conocía inconscientemente el problema que lo acompañó toda su vida profesional. Sin embargo, por más que trató de subestimarlo, ignorarlo y hasta neutralizarlo, éste siempre persistió. Se sabe que intentó superar la desventaja al integrarse a todas las sociedades de arquitectos, a la vez que buscó participar en el establecimiento de academias de arquitectura y arte. Como parte de esta estrategia de incorporación al medio que lo rechazaba, Pani tomó una de las decisiones más importantes de su vida: la fundación de la revista Arquitectura-México, espacio que manejó con gran habilidad política, pues ahí admitió a sus enemigos iniciales, presentó las obras de éstos y las difundió por todo el país. Nótese que la revista duró más de $\mathbf{4 0}$ años. Se puede decir entonces que en este espacio construyó las redes de poder y de lealtades que le faltaron al principio de su carrera, ya que es bien sabido que las relaciones existentes entre los políticos y los profesionales de la época tenían sus raíces en la Preparatoria Nacional.

Sea de esto lo que fuere, Pani se acostumbró a vivir con la representación ambivalente que construyeron a su alrededor sus colegas arquitectos. Sin embargo, para contrarrestarla diseñó y adoptó inteligentes estrategias, que se puede 'decir le rindieron muy buenos dividendos. Primero construyó una diferencia para distinguirse o ha-

Historia Oral de la Ciudad de México: Testimonios de sus Arquitectos (1940-1990), en la ciudad de México el 4 de julio de 1990, Instituto Mora, PHO 11/4 (1). cerse especial entre su grupo. Basándose en su educación en l'Ecole des Beaux-Arts, elaboró el mito de su excepcionalidad al interior de algunos medios arquitectónicos y políticos; segundo, se ganó un lugar dentro del gremio al vencer en todos los concursos de arquitectura que se convocaran, a pesar de la incredulidad de sus colegas, que las creían victorias conseguidas por "dedazo", y, para qué negarlo, también contribuyó a su éxito el peso de un pasado familiar, político y socialmente conveniente.

\section{CONCLUSIONES}

El seguimiento de la historia de la revalidación de los estudios y del reconocimiento del título, no sólo revela interesantes y selectivas prácticas que pintan el funcionamiento de una sociedad, de las pugnas que la dividen y de los pactos que gestionan sus partes para normalizar situaciones de conflicto, sino que además apunta, con el análisis de sus consecuencias, atractivas guías o, más bien, pistas para continuar el estudio de una historia de vida.

En efecto, la investigación de esta historia vale la pena por varias razones. Primero, porque permite interpretar cómo un individuo proyecta sus autorrepresentaciones y mitos o leyendas para mejor adaptarse y relacionarse con su grupo. En el caso de Mario Pani, su educación en la Escuela de Bellas Artes de París es la "distinción" que lo separa y lo hace especial con respecto a sus colegas arquitectos. Esta diferencia lo provee de los 


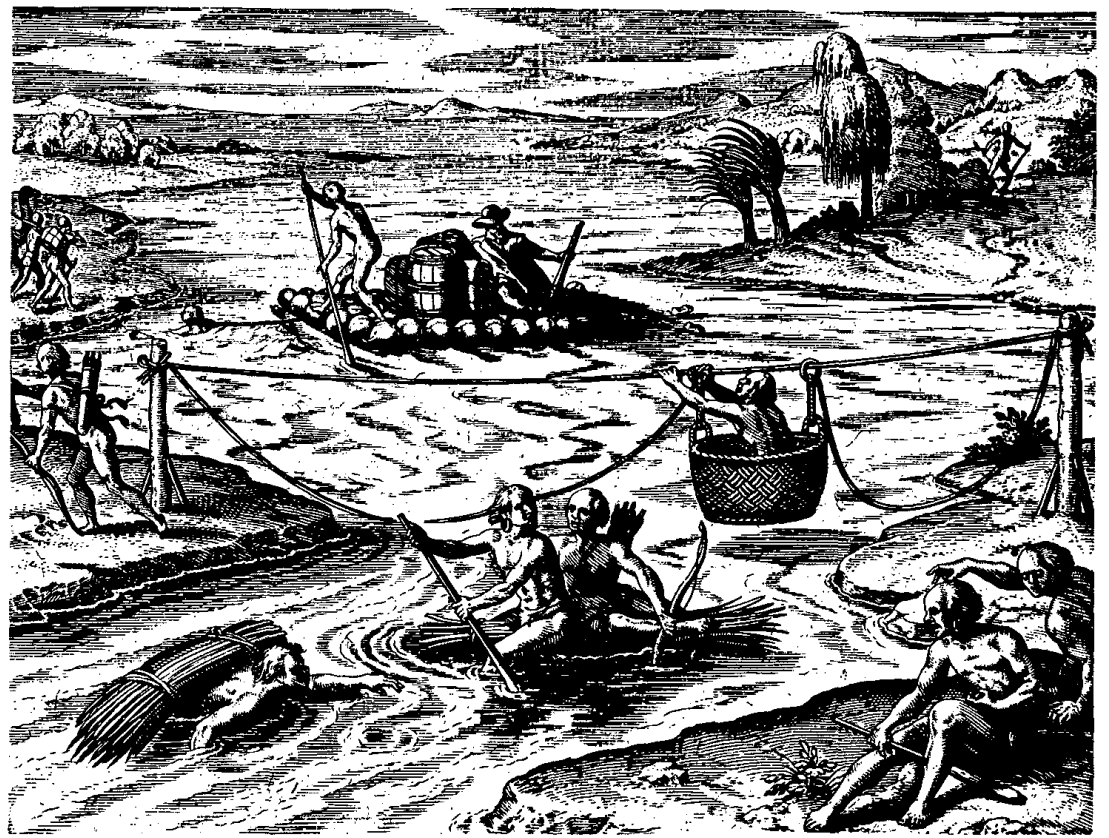

privilegios para decidir e influir dentro del gremio, a pesar de la clara oposición de algunos de sus miembros que, a su vez, comparten otra representación social de Pani. Segundo, porque muestra cómo el actor de una historia elige, consciente o inconscientemente, interesantes estrategias de vida para moverse con mayor libertad dentro del rigor de las reglas, consiguiendo así normalizarlas para su beneficio o infringirlas para acabar por romperlas definitivamente. Con su estrategia de la diferencia, Pani logró neutralizar los mitos o las representaciones que corrían entre la gente que lo juzgaba y se oponía a su incorporación a la práctica profesional. Al comprender esta situación, el arquitecto Pani ingresó a todas las organizaciones de arquitectos, fundó socicdades y academias, participó en concursos con la idea de negociar su cambio de posición dentro de esa red social de poder que le reservaba una participación limitada en el juego, aun a pesar de los capitales sociales y culturales que apostaba. Tercero, se puede ver cómo Mario Pani contempló, como parte del juego de sus estrategias, el infiltrarse en el entramado de las lealtades sociales tejidas por aquellos que lo 
observaban con desconfianza y le negaban la aceptación. Con esta táctica obtuvo, a final de cuentas, la asimilación esperada, aunque siempre recelosa, de muchos arquitectos que obviamente representaban a sus competidores. Claro, las relaciones que Pani tejió hacia afuera pero desde su despacho; su revista, dentro de la Escuela de Arquitectura, y al interior del círculo de amigos que heredó de las conexiones políticas de su padre, Arturo Pani, y de su tío, Alberto J. Pani, resultaron en conjunto inteligentes herramientas para cambiar, hasta cierto punto, las actitudes de los contrarios. Cuarto, la historia revela interesantes ángulos del carácter de Pani. Efectivamente, para el manejo del problema decide la lucha, pero de ninguna manera la confrontación intolerante, pues esto lo hubiera alejado del juego y sumido en la frustración improductiva, aunque también es claro que en este combate el agente tendrá que valerse de todas sus herramientas para competir. Esto naturalmente le creará problemas, pues se reforzarán las lecturas de esas representaciones que tendían a colocarlo en el plano de los políticos arbitrarios y manipuladores. Se le juzga nuevamente a partir de los códigos éticos y de honor que suelen anteponer los profesionales para dirimir disputas en esencia personales. Quinta, la historia es importante, porque sugiere un tema para la sociología de las profesiones. Apunta cómo la especialización propicia la selección y depuración de la fuerza de trabajo y la capilaridad social al interior de una sociedad, pero también subraya cómo los méritos y la preparación no bastan por sí solos para calificar en esta carrera de cambio de posiciones. Sexta y última, y quizá la más importante, plantea la complejidad de la construcción y deconstrucción de la memoria colectiva dominante. Sugiere cómo se conforma y cambia, ya que jamás es monolítica ni inalterable. Los actores con sus estrategias, elecciones conscientes e inconscientes, pueden construir y deconstruir la memoria colectiva dominante. Además, con estas lecturas y relecturas de la memoria colectiva dominante se retoman los aspectos objetivos y subjetivos de una trayectoria de vida. De ahí que la historia de Pani, desde el proceso de la revalidación hasta su consolidación como arquitecto reconocido, resulte tan interesante pues, dependiendo de los análisis y las verdades críticas y reflexivas que se infieran, las interpretaciones permitirán descubrir esos dos tipos de hombres a los que me referí al principio de este trabajo: el individuo que arriesga y participa en el juego, y aquel que, no importando los medios, sale adelante. Esa mezcla de genialidad heroica y maquiavelismo egocéntrico y prepotente ayuda a no perder de vista la complejidad de la vida humana y a probar también que estudiar una biografia, a partir de verdades a priori y acabadas, es siempre imposible, pues las verdades de una vida son siempre plurales y cambiantes. No es suficiente saber que ya murió la persona para juzgarla por sus actos, ya que la lectura de éstos siempre es incompleta. Las interpretaciones serán provisionales y sobrevivirán mientras cuenten con un consenso de verdad. 


\section{BIBLIOGRAFIA}

-Arce Gurza, Francisco, "El inicio de una nueva era, 1910-1945" en Francisco Arce Gurza, Milada Bazant et al, Historia de las profesiones en México, pról. de Josefina Zoraida Vázquez, El Colegio de México, 1982.

-Archives Nationales, Archives de l'Ecole Nationale Supérieure des Beaux-Arts et de l'Ecole Nationale Supérieure des Arts Décoratifs, Inventaire par Brigitte LabatPoussin, París, 1978 (Diffusé par La Documentation Francaise).

-Benjamin, Walter, "The storyteller: reflections on the works of Nikolai Leskov" en Illuminations, trad. Harry Kohn, 1955; reimp., Nueva York, 1968.

-Jodelet, Denise, "La representación social: fenómenos, conceptos y teoría" en S. Moscovici, Psicología social II. Pensamiento y vida social. Psicología social y problemas sociales, trad. de Rosenbaum, supervisión de Tomás Ibáñez, Paidós, Barcelona/Buenos Aires/México, 1984, reedición, 1986-1988 (Cognición y Desarrollo Social, II).

-Katzman, Israel, La arquitectura contemporánea mexicana, precedentes y desarrollo. Memorias VIII, INAH/SEP, México, 1963-1964.
-López Rangel, Rafael, Enrique Yáñez en la cultura arquitectónica mexicana, presentación de Javier Covarrubias, pról. cle María Teresa Ocejo Cázares, UAM-Azcapotzalco/Noriega Editores/Editorial Limusa, México, 1989.

-Luna Arroyo, Antonio, Juan O'Gorman. Autobiografía, antología, juicios criticos y documentación exhaustivas, Cuadernos Populares de Pintura Mcxicana Moderna, México, 1973.

-Mendiola, Alfonso, "Michel de Certeau: la búsqueda de la diferencia", Historia y Grafía, núm. 1, año 1, 1993.

-Thelen, David, Memory and american bistory, Indiana University Press, Bloomington e Indianápolis, 1990.

-Universidad Nacional Autónoma de México, Plan de estudios de la Facultad de Arquitectura, año 1930, Talleres Linotipográficos El Modelo, México, 1930.

-Universidad Nacional de México, Plan de estudios de la Escuela Nacional de Bellas Artes, año 1928, Publicaciones de la Secretaría de Educación Pública, t. XVII, núm. 4, Talleres Gráficos de la Nación, México, 1928.

-Villoro, Luis, "La cultura mexicana de 1910 a 1960 " en Cultura, ideas y mentalidades, introducción y selección de Solange Alberro, El Colegio de México, México, 1992 (Lecturas de Historia Mexicana, 6). 